\title{
MODEL-MODEL PEMBELAJARAN DAN PEMEFOLEHAN BAHASA KEDUA/ASING
}

\author{
Hanna Sundari \\ Universitas Indraprasta PGRI Jakarta \\ Pos-el: Hanna.sundari@gmail.com \\ Telepon: 085714778192
}

\begin{abstract}
Models of language learning and acquisition in the issue of second /foreign language learning and acquisition have not been discussed much so far. However, the concepts of how learners acquire and learn language are essential to know and understand by teachers/lecturers who involve in the field of practical language teaching. This article tries to give a description of both models of language in general and model of language learning and acquisition in regard to the nature, the position, and the types of models build upon the experts. The models of language learning and acquisition discussed are Tradisional Model, Levelt Model, Paul Nation Model, Swain Model, and ACCESS Model.
\end{abstract}

Key word: model, learning and acquisition, second/foreign language

\begin{abstract}
ABSTRAK
Model pembelajaran dan pemerolehan bahasa dalam kajian pemerolehan bahasa kedua/asing memang tidak terlalu banyak didiskusikan. Namun begitu, konsep mengenai bagaimana bahasa asing/kedua diperoleh dan dipelajari perlu diketahui dan dipahami oleh guru/dosen yang berkecimpung dalam dunia pembelajaran bahasa secara praktis. Paparan ini memberikan deskripsi mengenai model pembelajaran secara umum dan model pembelajaran dan pemerolehan bahasa kedua/asing dalam aspek pengertian, posisi dalam kajian pembelajaran bahasa kedua/asing dan macam-macam model yang diperoleh dari berbagai pandangan ahli. Model pembelajaran dan pemerolehan bahasa asing/kedua yang akan dibahas, diantaranya: Model Tradisional, Model Levelt, Model Paul Nation, Model Swain, dan Model ACCESS.
\end{abstract}

Kata kunci: model, pembelajaran dan pemerolehan, bahasa kedua/asing

\section{PENDAHULUAN}

Dalam kajian pembelajaran bahasa kedua/asing, terdapat berbagai istilah yang hampir semua istilah tersebut merujuk pada cara dan langkah yang dipilih dan diterapkan guru bahasa di kelas untuk memfasilitasi pembelajaran dan kefasihan bahasa siswa. Cara dan langkah tersebut dapat disebut sebagai pendekatan, metode, teknik, prosedur dan lainnya. Sehingga perlu dijelaskan definisi dan perbedaan istilah-istilah tersebut.

Pada akhir abad ke-19, para linguis dan spesialis bahasa berupaya meningkatkan kualitas pengajaran bahasa, namun terdapat perbedaan referensi 
mengenai pengetahuan umum dan teori yang berkaitan dengan bagaimana bahasa dipelajari dan bagaimana pengetahuan bahasa disajikan dan disusun. Kemudian, Edward Anthony pada 1963 mengidentifikasi tingkat konseptualisasi dan organisasi pembelajaran bahasa menjadi 3, yakni: pendekatan (approach), metode (method), dan teknik (technique). Pendekatan merupakan seperangkat asumsi yang saling terkait meliputi hakikat bahasa belajar, dan pengajaran. Sementara, metode adalah keseluruhan rencana untuk menyajikan sejumlah materi bahasa yang sistematik berdasar pada pendekatan tertentu. Dan selanjutnya, teknik berisi aktifitas-aktifitas yang spesifik sebagai perwujudan dari metode yang dipilih dan sejalan dengan pendekatan yang ditentukan(Brown, 2007:14).

Istilah dan konsep yang digagas Anthony masih banyak digunakan oleh guru bahasa dalam aplikasi pembelajaran di kelas. Kemudian, Richards and Rogers juga mereformulasi gagasan Anthony ke dalam satu konsep metode, yang terdiri dari 3 bagian: pendekatan, desain, dan prosedur. Metode laksana payung yang menaungi 3 bagian lainnya. Pendekatan dimaknai sebagai asumsi, keyakinan, dan teori tentang bahasa dan belajar bahasa. Sedangkan, desain berisi hubungan-hubungan teori-teori tersebut terhadap materi dan aktivitas kelas. Dan prosedur terdiri dari teknik and praktik yang berasal dari satu pendekatan dan desain tertentu(Brown, 2007: 14). Berikut adalah skema Metode menurut Richards dan Rogers.

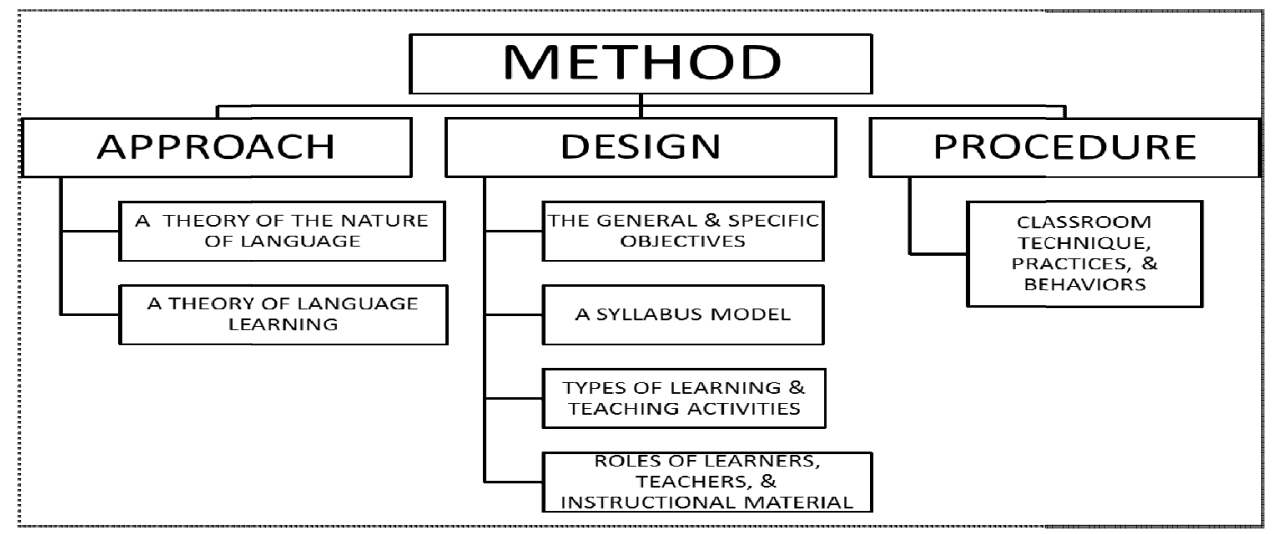

Gambar 1 Elemen dan Sub Elemen Dalam Metode (Richards \& Rogers, 2001:33)

Istilah metode dalam konsep Richards dan Rogers mendapat perluasan makna dan menaungi istilah-istilah lain. Hal ini dikemudian hari menjadi kebingungan dan ketidakjelasan istilah dalam pembelajaran bahasa. Belum lagi, adanya istilah kurikulum dan silabus dalam pembelajaran bahasa yang juga identik dengan desain bahasa. Brown (2007: 17) mencoba memperjelas dengan memberikan seperangkat definisi terhadap istilah-istilah tersebut, sebagai berikut:

1) Metodologi: praktik-praktik pedagogis umum, termasuk di dalamnya landasan teori dan penelitian yang relevan, dan segala sesuatu tentang "bagaimana mengajar". 
2) Pendekatan: keadaan dan keyakinan secara teoritis tentang hakikat bahasa, hakikat belajar bahasa dan penerapan keduanya dalam latar pendidikan.

3) Metode: seperangkat spesifikasi kelas agar tujuan-tujuan linguistik tercapai. Metode juga berisi khususnya mengenai peran dan perilaku guru dan siswa; secara umum juga berisi fitur linguistik, tujuan pembelajaran, urutan belajar dan materi ajar.

4) Teknik: berbagai variasi latihan, penugasan, aktivitis yang digunakan di kelas bahasa untuk mewujudkan tujuan pembelajaran.

Istilah-istilah yang telah didefinisikan oleh para ahli bidang bahasa tampaknya disesuaikan dengan perkembangan pembelajaran bahasa Inggris di dunia. Istilah metode dan pendekatan memang lebih sering digunakan, seperti pada Grammartranslation Method, Audiolingual Method, Direct Method, Oral Approach, Lexical Approach dan Natural Approach. Istilah metode dan pendekatan sudah lebih dulu dipakai sebelum dipahami lebih dalam pengertian dan perbedaan antar keduanya. Sehingga kedua istilah tersebut kerap saling tumpang tindih dalam pemakaian, terutama dalam kajian pembelajaran bahasa.

Sementara itu, istilah model pembelajaran baru digunakan saat kajian pembelajaran bahasa memasuki era pos-metode (post-method era). Model pembelajaran bahasa lebih khusus menyajikan kerangka teoretis mengenai pembelajaran dan pemerolehan bahasa dalam konteks pengajaran di kelas. Sementara, Istilah umum Models of Teaching pertama kali dikumandangkan oleh Bruce Joyce dan Marsha Weil dalam artikel ilmiah pada tahun 1972. Joyce dan Weil menyatakan bahwa pembelajaran dan pengajaran adalah hal yang nyaris sama sehingga sulit ditemukan perbedaan antar keduanya.

\section{METODE}

Paparan ini menggunakan pendekatan kepustakaan (library research) dengan menelusuri literatur yang relevan dengan topik bahasan. Tujuan artikel ini untuk memberikan paparan secara mendalam mengenai model pembelajaran secara umum, dan khususnya model pembelajaran dan pemerolehan bahasa kedua/asing berdasarkan pada referensi yang terdahulu maupun yang termutakhir. Sehingga diperoleh pemahaman yang komprehensif dan menyeluruh mengenai model pembelajaran dan pemerolehan bahasa kedua/asing.

\section{PEMBAHASAN}

Dari kerangka teoretis yang lebih umum, model pembelajaran, menurut Isjoni (2012: 147), merupakan strategi yang digunakan guru untuk meningkatkan motivasi belajar, sikap belajar di kalangan siswa, mampu berpikir kritis, memiliki keterampilan sosial, dan pencapaian hasil pembelajaran yang lebih. Model pembelajaran berisi strategi-strategi pilihan guru untuk tujuan-tujuan tertentu di kelas. Sementara, strategi, menurut Kemp (dalam Rusman, 2014: 132), merupakan suatu kegiatan pembelajaran yang harus dikerjakan oleh guru dan siswa agar tujuan pembelajaran tercapai secara efektif dan efisien. Sementara itu, Dick dan carey menyatakan strategi 
pembelajaran sebagai suatu perangkat materi dan prosedur pembelajaran yang digunakan secara bersama-sama untuk menimbulkan hasil belajar pada siswa. Satu strategi pembelajaran dapat menggunakan beberapa metode. Model pembelajaran juga dilandasi oleh berbagai prinsip dan teori pengetahuan, diantaranya prinsipprinsip pembelajaran, teori psikologis, sosiologis, analisis sistem, atau teori lain yang membantu (dalam Rusman, 2014:132). Sehubungan dengan itu, model pembelajaran merupakan seperangkat materi dan prosedur pembelajaran atas dasar landasan teoretis tertentu untuk tujuan pembelajaran tertentu.

Pendapat yang lebih komprehensif diungkapkan oleh Miftahul Huda. Model pembelajaran didefinisikan sebagai gambaran keseluruhan pembelajaran yang kompleks dengan berbagai teknik dan prosedur yang menjadi bagian pentingnya. Di dalam kompleksitas model pembelajaran, terdapat metode, teknik, dan prosedur yang saling bersinggungan satu dengan lainnya (Miftahul Huda, 2014). Sehingga model pembelajaran adalah satu perangkat pembelajaran yang kompleks yang menaungi metode, teknik, dan prosedur.

Sebagai ringkasan, definisi model pembelajaran dari Susan Ellis (1979: 275) akan melengkapi bahasan ini. Model pembelajaran merupakan strategi-strategi yang berdasar pada teori-teori dan penelitian yang terdiri dari rasional, seperangkat langkah-langkah dan tindakan yang dilakukan guru dan siswa, sistem pendukung pembelajaran dan metode evaluasi atau sistem penilaian perkembangan belajar siswa. Model pembelajaran hakikatnya menggambarkan keseluruhan yang terjadi dalam pembelajaran dari mulai awal, pada saat, maupun akhir pembelajaran pada tidak hanya guru namun juga siswa.

Berdasarkan pengertian-pengertian model pembelajaran di atas, setiap model pembelajaran memiliki ciri-ciri, sebagai berikut.

1) Berdasarkan teori pendidikan dan teori belajar dari para ahli tertentu.

2) Mempunyai misi atau tujuan pendidikan tertentu.

3) Dapat dijadikan pedoman perbaikan kegiatan belajar mengajar di kelas.

4) Memiliki bagian-bagian model yang dinamakan: (a) urutan langkah-langkah pembelajaran (syntax), (b) prinsip-prinsip reaksi, (c) sistem sosial, dan (d) sistem pendukung.

5) Memiliki dampak sebagai akibat terapan model pembelajaran, meliputi: dampak pembelajaran berupa hasil belajar yang terukur dan dampak pengiring berupa hasil belajar jangka panjang.

6) Adanya desain instruksional atau persiapan mengajar dengan berpedoman pada model pembelajaran yang dipilih.

Dengan demikian, dapat disimpulkan bahwa model pembelajaran merupakan seperangkat strategi yang berdasarkan landasan teori dan penelitian tertentu yang meliputi latar belakang, prosedur pembelajaran, sistem pendukung dan evaluasi pembelajaran yang ditujukan bagi guru dan siswa untuk mencapai tujuan pembelajaran tertentu yang dapat diukur.

\section{Model Pembelajaran}


Seperangkat strategi pembelajaran yang berdasarkan teori dan penelitian disebut juga model pembelajaran. Berdasarkan perbedaan kerangka referensi belajar dan pengajaran dan perbedaan konsepsi tujuan dan media pendidikan, Bruce Joyce dan Masha Weil membagi model pembelajaran menjadi empat kelompok besar (family), yakni: model pemrosesan informasi, model interaksi sosial, model personal, dan model modifikasi perilaku (Joyce dan Weil, 1972: 2). Tiap model pembelajaran memiliki ciri-ciri dan pengembang model pembelajaran tersendiri.

\section{1) Model Pembelajaran Pemrosesan Informasi}

Model pembelajaran ini berkaitan dengan kapabilitas (kecakapan) seseorang/siswa dalam memproses informasi dan sistem yang dapat meningkatkan kapabilitas tersebut. Dengan pemrosesan informasi, terdapat cara-cara bagaimana seseorang merespon stimulus dari lingkungan, mengorganisir data, memaknai masalah, mengembangkan konsep, dan solusi atas masalah tersebut sehingga kemudian menerapkan simbol-simbol verbal dan non-verbal.

Kapabilitas/kecapakan merupakan luaran dari pemrosesan informasi, yang terdiri: informasi verbal, kecakapan interlektual, strategi kognitif, sikap, dan kecakapan motorik (Rusman, 2014: 139-140). Selain dari itu, berkaitan dengan model pembelajaran pemrosesan informasi, terdapat beberapa hal yang perlu diperhatikan seperti berikut.

a) Melakukan tindakan untuk menarik perhatian siswa

b) Memberikan informasi mengenai tujuan pembelajaran dan topik yang akan dibahas.

c) Merangsang siswa untuk memulai aktivitas pembelajaran.

d) Menyampaikan isi pembelajaran sesuai topik yang direncanakan.

e) Memberikan bimbingan bagi aktivitas siswa dalam pembelajaran.

f) Memberikan penguatan dan umpan balik (feedback) terhadap perilaku siswa.

g) Melaksanakan penilaian proses dan hasil.

h) Memberi kesempatan kepada siswa untuk bertanya dan menjawab berdasar pengalaman.

Berikut ini merupakan model-model pembelajaran yang termasuk dalam kategori model pembelajaran pemrosesan informasi (Joyce dan Weil, 1972: 4--5):

Tabel 1 Model-model Pembelajaran Pemrosesan Informasi (Joyce dan Weil, 1972)

\begin{tabular}{|l|l|l|}
\hline \multicolumn{1}{|c|}{ Model } & \multicolumn{1}{|c|}{ Tokoh } & \multicolumn{1}{|c|}{ Tujuan } \\
\hline Model Induktif & Hilda Taba & $\begin{array}{l}\text { Pengembangan proses berpikir } \\
\text { induktif dan penalaran akademik, } \\
\text { juga kecakapan personal dan sosial }\end{array}$ \\
\hline $\begin{array}{l}\text { Model Latihan } \\
\text { Inquiri }\end{array}$ & Richard Suchman & $\begin{array}{l}\text { Pengembangan proses berpikir } \\
\text { induktif dan penalaran akademik, } \\
\text { juga kecakapan personal dan sosial }\end{array}$ \\
\hline $\begin{array}{l}\text { Model Inquiri } \\
\text { Ilmiah }\end{array}$ & Joseph J. Schwab & $\begin{array}{l}\text { Pengajaran sistem penelitian satu } \\
\text { disiplin ilmu dan peningkatan }\end{array}$ \\
\hline
\end{tabular}




\begin{tabular}{|l|l|l|}
\hline $\begin{array}{l}\text { Model } \\
\begin{array}{l}\text { Pembelajaran } \\
\text { Jurisprudensial }\end{array}\end{array}$ & $\begin{array}{l}\text { Donald Oliver dan } \\
\text { James P. Shaver }\end{array}$ & $\begin{array}{l}\text { Pengajaran kerangka berpikir } \\
\text { jurisprudensial dan cara berpikir } \\
\text { guna menyelesaikan masalah sosial }\end{array}$ \\
\hline Penemuan Konsep & Jerome Bruner & Pengembangan penalaran induktif \\
\hline $\begin{array}{l}\text { Perkembangan } \\
\text { Kognitif }\end{array}$ & $\begin{array}{l}\text { Jean Piaget } \\
\text { Irving Sigel } \\
\text { Edmund Sullivan }\end{array}$ & $\begin{array}{l}\text { Peningkatan perkembangan } \\
\text { intellectual general khususnya } \\
\text { penalaran logika juga } \\
\text { perkembangan sosial moral }\end{array}$ \\
\hline $\begin{array}{l}\text { Model Panjut (Advance } \\
\text { Organizer) }\end{array}$ & David Ausubel & $\begin{array}{l}\text { Peningkatan efisiensi kecakapan } \\
\text { pemrosesan informasi sehingga } \\
\text { diserap dengan penuh makna dan } \\
\text { mampu dikaitkan dengan seluruh } \\
\text { pengetahuan }\end{array}$ \\
\hline
\end{tabular}

\section{2) Model Pembelajaran Interaksi Sosial}

Model pembelajaran interaksi sosial bermula dari konsep masyarakat dan perkembangan relasi interpersonal. Model ini menggambarkan bahwa hakikat manusia adalah menjalin relasi sosial dan menciptakan masyarakat yang lebih baik. Inquiri yang ilmiah diperoleh dari model ini. Model ini didasari teori belajar Gestalt (field theory) yang menyatakan bahwa objek/peristiwa dipandang sebagai keseluruhan bagian. Maka, pembelajaran akan bermakna bila diberikan secara utuh. Aplikasi teori Gestalt dalam pembelajaran, diantaranya: pengalaman (insight), pembelajaran bermakna, perilaku bertujuan, dan prinsip ruang hidup. Pembelajaran memampukan siswa memecahkan masalah berdasarkan insight. Materi ajar memiliki makna yang jelas bagi kehidupan siswa dan berkaitan dengan lingkungan belajar siswa (Rusman, 2014: 136-137). Berikut adalah model-model pembelajaran interaksi sosial:

Tabel 2 Model-model Pembelajaran Interaksi Sosial (Joyce dan Weil, 1972)

\begin{tabular}{|l|l|l|}
\hline \multicolumn{1}{|c|}{ Model } & \multicolumn{1}{|c|}{ Tokoh } & \multicolumn{1}{c|}{ Tujuan } \\
\hline $\begin{array}{l}\text { Investigasi } \\
\text { Kelompok }\end{array}$ & $\begin{array}{l}\text { Herbert Thelen } \\
\text { dan John Dewey }\end{array}$ & $\begin{array}{l}\text { Pengembangan keterampilan berpartisipasi } \\
\text { dalam proses sosial melalui perpaduan } \\
\text { keterampilan sosial interpersonal dan inquiri } \\
\text { akademik, juga perkembangan personal }\end{array}$ \\
\hline $\begin{array}{l}\text { Inquiri } \\
\text { Sosial }\end{array}$ & $\begin{array}{l}\text { Byron Massiales } \\
\text { dan Benjamin } \\
\text { Cox }\end{array}$ & $\begin{array}{l}\text { Pemecahan masalah sosial melalui inquiri } \\
\text { akademik dan penalaran logis }\end{array}$ \\
\hline $\begin{array}{l}\text { Metode } \\
\text { Laboratory }\end{array}$ & $\begin{array}{l}\text { National Training } \\
\text { Laboratory }\end{array}$ & $\begin{array}{l}\text { Pengembangan keterampilan interpersonal } \\
\text { dan kelompok melalui kesadaran personal dan } \\
\text { fleksibilitas }\end{array}$ \\
\hline
\end{tabular}

\section{3) Model Pembelajaran Personal}


Model pembelajaran personal berpusat pada individu sebagai sumber gagasan belajar. Kerangka acuan ini menyoroti perkembangan personal dan proses bagaimana individu membangun dan menyusun realita. Kerangka ini juga menekankan pada psikologi personal dan kehidupan emosional individu. Model ini berorientasi pada teori-teori humanistik, teori-teori yang dikemukakan oleh Abraham Maslow, R. Rogers, Buhler dan Arthur Comb. Beberapa implikasi teori humanistik dalam pendidikan, diantaranya: bertingkah laku dan belajar merupakan hasil pengamatan, tingkah laku yang ada dapat dilakukan (learning to do), aktualisasi diri adalah dorongan dasar individu, sebagian tingkah laku individu merupakan hasil konsepsi sendiri, mengajar bukan yng terpenting tetapi belajar siswa adalah sangat penting (learning how to learn), dan mengajar dipahami sebagai membantu individu mengembangkan suatu hubungan yang produktif dengan lingkungan (Rusman, 2014: 142--143. Berikut adalah model-model pembelajaran yang mengaju pada kerangka acuan model pembelajaran personal (Joyce dan Weil, 1972: 5).

\section{Tabel 3 Model Pembelajaran Personal}

\begin{tabular}{|c|c|c|}
\hline Model & Tokoh & Tujuan \\
\hline $\begin{array}{ll}\text { Pengajaran } & \text { Tidak } \\
\text { Langsung } & \text { (non- } \\
\text { directive) } & \\
\end{array}$ & $\begin{array}{l}\text { Carl } \\
\text { Rogers }\end{array}$ & $\begin{array}{l}\text { Pembentukan kecakapan pembelajaran mandiri } \\
\text { melalui pemahaman diri, pengamatan diri, dan } \\
\text { konsep diri }\end{array}$ \\
\hline $\begin{array}{l}\text { Model Pertemuan } \\
\text { Kelas }\end{array}$ & $\begin{array}{l}\text { William } \\
\text { Glasser }\end{array}$ & $\begin{array}{l}\text { Pembentukan pemahaman dan tanggung jawab } \\
\text { diri yang memiliki keuntungan tersembunyi } \\
\text { secara sosial }\end{array}$ \\
\hline Latihan Kesadaran & $\begin{array}{l}\text { William } \\
\text { Schurtz } \\
\text { dan Fritz } \\
\text { Perls }\end{array}$ & $\begin{array}{l}\text { Peningkatan } 4 \text { kacapakan personal untuk } \\
\text { eksplorasi diri dan kesadaran diri dan } \\
\text { penekanan pada kesadaran dan pemahaman } \\
\text { interpersonal }\end{array}$ \\
\hline Model Sintektik & $\begin{array}{l}\text { Willian } \\
\text { Gordon } \\
\end{array}$ & $\begin{array}{l}\text { Perkembangan personal atas kreativitas dan } \\
\text { pemecahan masalah yang kreatif. }\end{array}$ \\
\hline $\begin{array}{l}\text { Model Sistem } \\
\text { Konseptual }\end{array}$ & $\begin{array}{l}\text { David. E. } \\
\text { Hunt }\end{array}$ & $\begin{array}{l}\text { Peningkatan kompleksitas dan fleksibilitas } \\
\text { personal }\end{array}$ \\
\hline
\end{tabular}

\section{4) Model Pembelajaran Modifikasi Perilaku}

Model pembelajaran modifikasi tingkah laku telah mengembangkan sistem yang efisien dalam upayan penyusunan aktivitas-aktivitas belajar dan membentuk perilaku melalui manipulasi penguatan. Model pembelajaran ini bertitik tolak pada teori belajar behaviorisme yang berfokus pada perubahan perilaku psikologis dan perilaku yang tak teramati (Rusman, 2014: 143--144). Rusman meyebutkan penerapan model modifikasi tingkah laku dalam pembelajaran, diantaranya: guru selalu perhatian terhadap tingkah laku belajar siswa, modifikasi tingkah laku yang berkemampuan rendah melalui pemberian penghargaan, dan penerapan prinsip pembelajaran individual. Salah satu model pembelajaran yang mengacu pada model pembelajaran tingkah laku adalah model pembelajaran operant-conditioning yang dipelopori oleh B. F. Skinner (Joyce dan Weil, 1972: 6). 


\section{Model Pembelajaran dan Pemerolehan Bahasa}

Proses pembelajaran dan pemerolehan bahasa baik bahasa pertama maupun kedua/asing memiliki karakteristik tertentu, yang dapat berbeda atau juga menjadi bagian dari proses pembelajaran yang umum. Khususnya pada pembelajaran dan pemerolehan bahasa kedua/asing, terdapat lima model pembelajaran yang menggagas kerangka dan asumsi teoretis yang berisi prinsip dan standar bagi pembelajaran di kelas bahasa, yakni: Model Tradisional, Model Levelt, Model Paul Nation, Model Swain, dan Model ACCESS (dalam Funk, 2012: 298--331). Berikut empat model pembelajaran bahasa:

\section{1) Model Pembelajaran dan Pemerolehan Tradisional}

Pembelajaran bahasa tradisional mengacu pada pembelajaran bahasa yang berorientasi pada akurasi tata bahasa, dan sedikit perhatian pada keterampilan lisan. Dengan latar interaksi yang sebagian besar berpusat pada guru, model pembelajaran bahasa mengarah pada ketepatan dan pengetahuan tata bahasa. Model pembelajaran ini sering disebut focus-on-forms approach, yakni pendekatan yang berfokus pada bentuk.

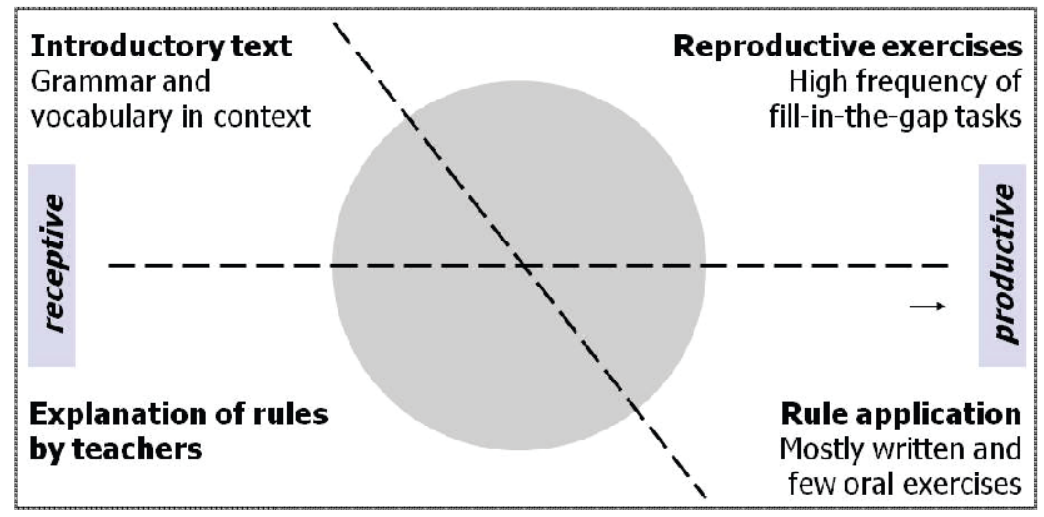

Gambar 2 Model Pembelajaran Tradisional: Focus-on-forms

\section{2) Model Pembelajaran dan Pemerolehan Bahasa Levelt}

Model pembelajaran bahasa yang digagas oleh William Levelt pada dasarnya merupakan model produksi bahasa oral. Kemudian, De Bot menerapkan model ini pada pemerolehan bahasa kedua, yang ternyata produksi baik bahasa pertama maupun kedua berkembang dalam jalur yang serupa. Levelt membedakan antara ujaran yang disadari (conscious speech act) yang berisi apa yang ingin disampaikan dan tindakan yang disengaja dengan ujaran yang tanpa sadar yang merupakan proses otomatis. Model pembelajaran dan pemerolehan bahasa ini memberikan keunggulan, diantaranya: a)Mempertimbangkan dasar leksikal dalam pembelajaran bahasa asing, termasuk tata bahasa, dan mendukung sepenuhnya pendekatan leksikal (lexical approach), b) Membedakan paradigma eksplisit dan implisit maupun proses sadar 
dan tanpa sadar dalam pemerolehan bahasa, bahkan menambahkan konsep lokalisasi fungsi otak, dan c) Berorientasi pada output sehingga menekankan pada pentingnya kompetensi oral/lisan yang juga merupakan tujuan utama pada pendekatanpendekatan pembelajaran bahasa modern. Konsisten dengan konsep-konsep pembelajaran bahasa di masa pos-metode, model pembelajaran Levelt ini menerapkan pembelajaran berbasis penugasan dengan diawali tugas pragmatik eksplisit yeng mengacu pada ujaran/tindak tutur dan pertimbangan intensional yang disengaja.

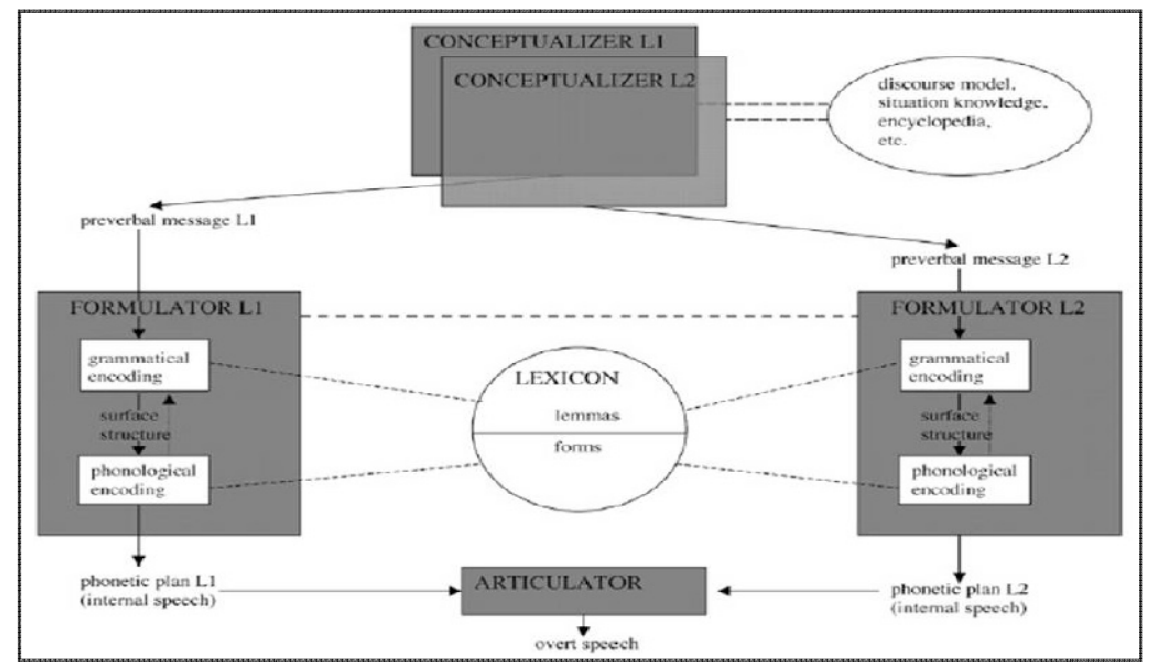

Gambar 3 Model Pembelajaran Bahasa De Bot (Funk, 2012)

\section{3) ModelPembelajaran dan Pemerolehan Bahasa Paul Nation}

Model pembelajaran bahasa menekankan pada keseimbangan distribusi aktivitas-aktivitas dalam empat area bahasa. Sehingga model ini disebut sebagai "the four strands". Dengan berorientasi pada output bahasa, Nation menyatakan keseimbangan perlu terjadi dalam aktivitas-aktivitas, meliputi: input bermakna, struktur bahasa, output bermakna, dan latihan kefasihan bahasa yang berlandaskan penelitian empirik dan tes.

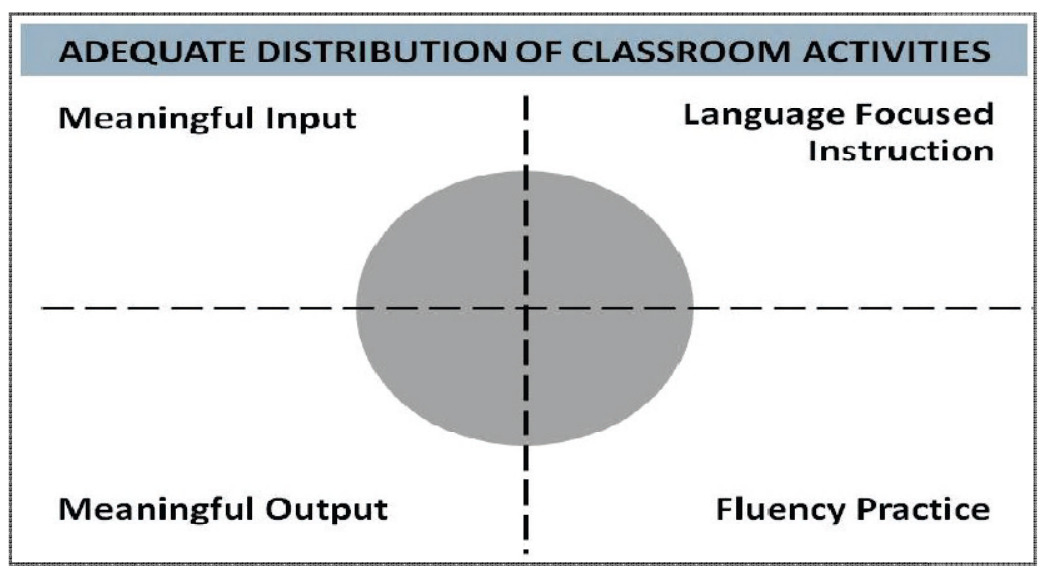


Model pembelajaran ini juga bertitik tolak pada pembelajaran berbasis tugas (task-based learning) yang berisikan bentuk-bentuk input bermakna dipadukan dengan output bahasa dan latihan kefasihan bahasa.

\section{4) Model Pembelajaran dan Pemerolehan Bahasa Swain}

Dalam model ini, Swain menegaskan bahwa pembelajaran dan pemerolehan terjadi pada siswa selama diberi kesempatan memproduksi bahasa. Siswa memberikan perhatian yang besar pada input bahasa pada saat siswa tidak mampu memahami kata/frase yang mereka baca/dengar. Merril Swain (1995, dalam Mackey, Abbuhl dan Gass, 2012: 8) meyakini bahwa input yang mudah dipahami tidaklah cukup, apabila pembelajar tidak diberikan kesempatan untuk berbicara dan menulis bahasa maka keterampilan produktif akan tertinggal dibandingkan dengan keterampilan reseptif. Pandangan ini merupakan titik awal Swain mengembangkan hipotesis output.

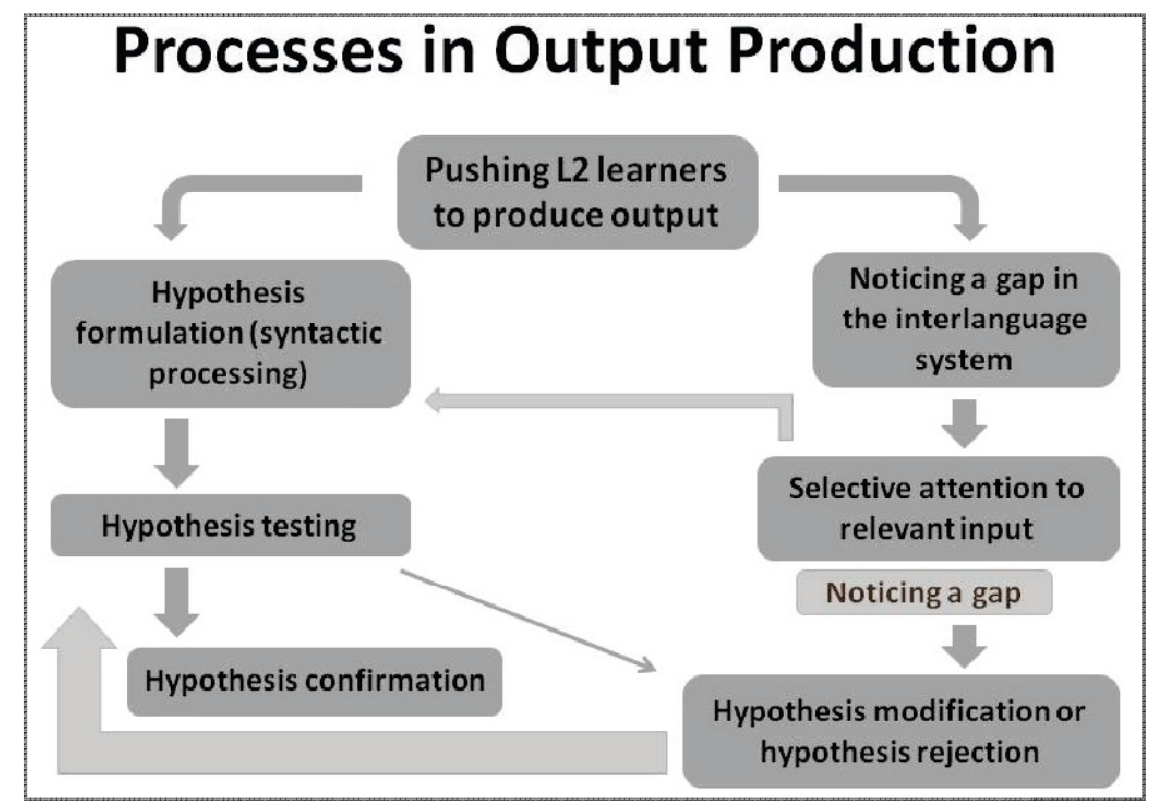

Gambar 5 Proces dalam Produksi Bahasa oleh Swain (Funk, 2012)

Output bahasa merupakan bahasa yang dihasilkan oleh pembelajar bahasa baik dalam berbicara maupun menulis (Mayo, 2013: 217). Pada umumnya output bahasa tidak dianggap sebagai cara menciptakan pengetahuan,tetapi hanya sekedar praktekpraktek bahasa yang telah dipelajari. Tetapi Swain (dalam Mayo, 2013: 217) 
menyatakan bahwa kelas yang melimpah input dan berlangsung komunikatif pun belum tentu mencapai kefasihan bahasa target. Namun, kelas (guru) perlu mendorong agar siswa menghasilkan bahasa sebanyak mungkin. Swain mengemukakan peran output dalam pemerolehan (dalam Mackey, Abbuhl dan Gass, 2012: 8), yakni: a) kesempatan bagi siswa untuk melatih dan membiasakan produksi bahasa, b) kesempatan bagi siswa menyusun hipotesis atas bahasa target yang dipelajari, c) mendorong pembelajar fokus pada struktur bahasa, dan d) agar pembelajar perhatian akan kesenjangan antarbahasa (interlanguage). Output merupakan wadah bagi siswa untuk tidak hanya mengulang input bahasa yang telah diterima namun lebih dari itu juga menciptakan dan memadukan secara kreatif fitur bahasa baru dan lama sehingga saat bersamaan terjadi peningkatan komprehensi dan produksi bahasa.

\section{5) Model Pembelajaran dan Pemerolehan Bahasa ACCESS}

Model pembelajaran ACCESS dikembangkan oleh Elizabeth Gatbontom dan Norman Segalowitz. istilah ACCESS merupakan singkatan dari automatization, communication, context of, essential, speech, dan segments. Model ini mendukung tujuan pembelajaran yang berorientasi pada kemampuan komunikatif atau Pembelajaran Bahasa Komunikatif dengan memberikan penyesuaian pada pembiasaan dan otomatisasi yang perlu dilakukan guru kepada siswa. Model ACCESS terdiri dari 3 fase pembelajaran sebagai berikut.

1) Fase otomatisasi kreatif

Pra-tugas: berisi pengenalan tema/topik, penentuan kesiapan siswa, pemberian tugas, menghasilkan segmen-segmen ujaran yang penting.

Tugas utama: siswa terlibat dalam tugas

Contoh Tugas: pemecahan masalah, bermain peran, permainan, dan simulasi

2) Fase konsolidasi bahasa

Tujuan: menguatkan control siswa terhadap ujaran-ujaran yang bermasalah.

Contoh tugas: kefasihan, akurasi, dan tugas tata bahasa

3) Fase komunikasi bebas

Tujuan: menilai penggunaan ujaran-ujaran dalam konteks

Prosedur: siswa terlibat dalam aktivitas komunikasi bebas

Contoh aktivitas: pemecahan masalah, bermain peran dan permainan.

\section{PENUTUP}

Tidak hanya sekadar aktivitas dan tugas belajar di kelas, model pembelajaran merupakan seperangkat strategi yang berdasarkan landasan teori dan penelitian tertentu yang meliputi latar belakang, prosedur pembelajaran, sistem pendukung dan evaluasi pembelajaran yang ditujukan bagi guru dan siswa untuk mencapai tujuan pembelajaran tertentu yang dapat diukur. Khususnya pada pembelajaran bahasa kedua/asing, model pembelajaran dan pemerolehan bahasa kedua/asing pada mulanya 
berorientasi pada bentuk bahasa (forms). Namun, seiring kebutuhan komunikasi, model pembelajaran lebih menekankan pada output bahasa.

\section{DAFTAR PUSTAKA}

Brown, H. D. 2007. Teaching by Principles: An Interactive Approach to Language Pedagogy. New York: Pearson Education, Inc.

Ellis, S. S. 1979. "Models of Teaching: A Solution to the Teaching Style/Learning Style Dilemma". Educational Leadership, (pp. 274--277.

Funk, H. 2012." Four Model of Language Learning and Acquisition and Their Methodological Implication for Textbook Design". Electronic Journal of Foreign Language Teaching, Vol. 9, Sippl. 1.(pp 298--311).

Huda , M. 2014. Model-Model Pengajaran dan Pembelajaran: Isu-isu Metodis dan Paradigmatis. Yogyakarta: Pustaka Pelajar.

Isjoni. 2012. "Efektivitas Model Kooperatif dalam Pelajaran Sejarah di Sekolah". Dalam Isjoni dan M. A. Hj. Ismail, Model-Model Pembelajaran Mutakhir: Perpaduan Indonesia-Malaysia (pp. 145--170). Yogyakarta: Pustaka Pelajar.

Joyce, B., \& Weil, M. 1972. "Conceptual Complexity, Teaching Style and Models of Teaching". Annual Meeting of National Council for the Social Studies (pp. 1-14). Boston: Education Resources Information Center (ERIC).

Mackey, A., Abbuhl, R., \& Gass, S. M. 2012. "Interactionist Approach". In S. M. Gass, \& A. Mackey, The Routledge Handbook of Second Language Acquisition (pp. 7--23). New York: Routledge Taylor \& Francis Group.

Mayo, M. d., \& Soler, E. A. 2013. "Negociated Input and Output/Interaction". In J. Herschensohn, \& M. Young-Scholten, The Cambridge Handbook of Second Language Acquisition (pp. 210--229). New York: Cambridge University Press.

Richards, J. C., \& Rodgers, T. S. 2001. Approaches and Methods in Language Teaching. Cambridge: Cambridge University Press.

Rusman. 2014. Model-Model Pembelajaran: Mengembangkan Profesionalisme Guru Edisi Kedua. Jakarta: PT RajaGrafindo Perkasa. 